\title{
Carcinoma renal papilar con metástasis sincrónica en el cordón espermático
}

\author{
Pascual Samaniego M, González Núñez Mª̂́a*, Bravo Fernández I, Ruiz Serrano M, \\ Ramos Martín JA, García González A.
}

Servicios de Urología y de *Anatomía Patológica. Hospital San Pedro de Alcántara. Cáceres.

Actas Urol Esp. 2007;31(4):404-410

\section{RESUMEN}

CARCINOMA RENAL PAPILAR CON METÁSTASIS SINCRÓNICA EN EL CORDÓN ESPERMÁTICO.

El carcinoma de células renales papilar (CCRP) se ha relacionado con porcentajes de supervivencia superiores y tasas de mortalidad por cáncer metastático inferiores respecto al carcinoma de células renales convencional. Presentamos un caso de comportamiento agresivo de acuerdo a la suma de características infrecuentes para esta variante histológica, como el tamaño tumoral superior a $10 \mathrm{~cm}$, la infiltración severa de la grasa perirrenal y de la glándula suprarrenal homolateral, la trombosis tumoral de la vena renal y de la vena cava infradiafragmática, la afectación adenopática retroperitoneal, un alto grado nuclear y la asociación en el momento del diagnóstico de una metástasis a distancia única sincrónica en el cordón espermático derecho, habiéndose comunicado esta última circunstancia en tres casos previos. La diferenciación pronóstica de la variante papilar resulta controvertida ante casos de este tipo, planteando la necesidad de obtener mejores perfiles diferenciales citogenéticos y moleculares para la clasificación de esta entidad histológica.

Palabras clave: Cáncer de riñón. Histología. Metástasis. Cordón espermático.

\section{ABSTRACT}

SYNCHRONOUS METASTASES OF THE SPERMATIC CORD FROM PAPILLARY RENAL CELL CARCINOMA

Papillary renal cell carcinoma has been related with higher survival rate and lower metastatic cancer mortality rate than clear renal cell carcinoma. We present an aggressive case related to unusual features for this histological type, like a tumor size higher than ten $\mathrm{cm}$, great perirrenal fat and suprarenal gland infiltration, tumoral thrombosis of the infrahepatic cava vein, retroperitoneal adenopatic tumoral infiltration, high nuclear grade and synchronous solitary distant organ metastases of the right spermatic cord, finding three previous cases in the literature with this last feature. Prognostic implication of the papillary renal cell carcinoma type is unclear in cases like this, so probably we need better molecular and cytogenetic studies to get a correct classification of this histological type.

Keywords: Kidney cancer. Histology. Metastases. Spermatic cord.

$\mathrm{L}$ a variante histológica papilar del carcinoma de células renales (CCRP) supone un 10-15\% del total. Clásicamente tiende a ser esporádico, unilateral, multifocal, de pequeño tamaño, de bajo grado nuclear, hipovascularizado, con abundantes áreas intratumorales de necrosis y hemorragia, limitado al riñón en el momento del diagnóstico y con características citogenéticas propias, habiéndosele asociado un pronóstico más favorable por presentarse con mayor frecuencia en estadios más preco$\operatorname{ces}^{1}$ y con menor potencial de malignidad, encontrándose supervivencias más prolongadas independientemente del estadio, respecto al carcinoma de células renales convencional $(\mathrm{CCRC})^{2}$.

Abreviaturas: CCRC: Carcinoma de células renales convencional. CCRP: Carcinoma de células renales papilar. ECOG: Eastern Cooperative Oncology Group. RMN: Resonancia magnética nuclear. 
Sin embargo, estudios más recientes ponen en duda este mejor pronóstico, ante la mayor incidencia de tumores como el que presentamos, encontrando correlación entre el grado nuclear, el estadio tumoral, la afectación ganglionar, la existencia de trombo tumoral venoso, el tamaño del tumor, la invasión del tejido adiposo perinéfrico y la presencia de metástasis sincrónicas ${ }^{3}$. La diferenciación del CCRP en dos subtipos de Delahunt y Eble $^{4}$ con distinto comportamiento clínico y pronóstico y las implicaciones de las características inmunohistoquímicas y citogenéticas pueden ayudar a una mayor estratificación de esta variante tumoral que mejore la valoración pronóstica.

A continuación se comentan las características atípicas del caso aportado, siendo entre ellas la presentación de metástasis sincrónica y solitaria a nivel del cordón espermático derecho el hallazgo más excepcional, habiéndose publicado tres casos previos de estas características ${ }^{5-7}$, si bien ninguno de ellos correspondiente a la variante histológica papilar.

\section{CASO CLÍNICO}

Varón de 68 años de edad, con antecedentes de hipertensión arterial y cólicos nefríticos expulsivos bilaterales, que ingresó por urgencias por hematuria macroscópica asintomática total con expulsión de coágulos de dos días de evolución y palpación de un bultoma indoloro en el hemiescroto derecho en los dos meses previos a la consulta. No refería anorexia ni perdida de peso y presentaba un nivel de actividad según ECOG de 1. En la exploración abdominal bimanual se palpaba una masa en hipocondrio y vacío derechos, mate a la percusión, indolora y no desplazable, siendo la puñopercusión derecha sensible. No presentaba edema de extremidades inferiores ni circulación venosa colateral abdominal. A nivel escrotal, por encima del polo superior del testículo derecho, en la confluencia de la cabeza del epidídimo con el cordón espermático, se detectó una masa indurada no dolorosa de unos $4 \mathrm{~cm}$ de diámetro, siendo ambos testículos de volumen, consistencia y localización normales. Próstata de volumen II/IV fibroelástica al tacto rectal.

Analíticamente se detectó una leve anemización, con $\mathrm{Ht}^{\circ}: 33,2 \%$ y Hb: 10,9 g/dl, una creati- nina de $1.3 \mathrm{mg} / \mathrm{dl}$, LDH: 1091UI/L, GOT: $147 \mathrm{mU} / \mathrm{ml}$, GPT: $83 \mathrm{mU} / \mathrm{ml}$, fosfatasa alcalina: $58 \mathrm{UI} / \mathrm{L}$ y proteínas totales: $4.4 \mathrm{~g} / \mathrm{dl}$. La serie blanca, el estudio de coagulación y la analítica de orina fueron normales, no evidenciándose proteinuria, trombocitosis, hipercalcemia ni hiperfosfatemia. El PSA fue de 5,79 $\mathrm{ng} / \mathrm{ml}$ y los valores de $\beta$-HCG y alfa-fetoproteína resultaron normales (14,9 UI/L y $1,55 \mathrm{ng} / \mathrm{ml}$ respectivamente). La radiografía de tórax y el ECG no aportaron datos patológicos. La ecografía abdominal informaba de un riñón derecho aumentado de tamaño con una lesión sólida, heterogénea, de unos $8 \mathrm{~cm}$ en su polo superior compatible con cáncer de células renales, así como una colección líquida de unos 8 $\mathrm{cm}$ en su polo inferior y presencia de adenopatías patológicas a nivel hiliar. Riñón izquierdo sin hallazgos patológicos, angioma hepático derecho de $5 \mathrm{~cm}$ y presencia de colelitiasis múltiple. Dada la presencia de hematuria se solicitaron urografias intravenosas, apreciándose un riñón derecho no funcionante con imágenes de efecto masa improntando en el hilio hepático y en el polo inferior. Morfofunción renal normal izquierda y presencia de un cálculo vesical de unos $2 \mathrm{~cm}$.

Como estudio de extensión se realizó una RMN abdominopélvica (Figs. 1 y 2) aportando los siguientes hallazgos: masa renal derecha heterogénea, sólida y polilobulada con diámetros de 10x12x15 cm presentando signos de infiltración severa del espacio perirrenal a nivel posterosuperior, con circulación colateral y trombosis de la vena renal derecha con extensión a la vena cava infrahepática, midiendo dicho trombo $6.5 \mathrm{~cm}$ en

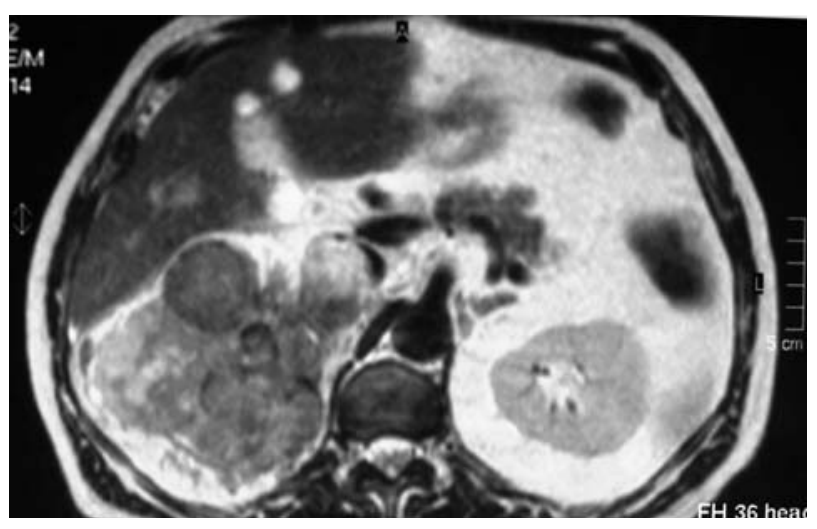

FIGURA 1. RMN. Cortes transversales que muestran una masa renal derecha sólida polilobulada con presencia de trombo tumoral ocupando la luz de la vena cava inferior. 

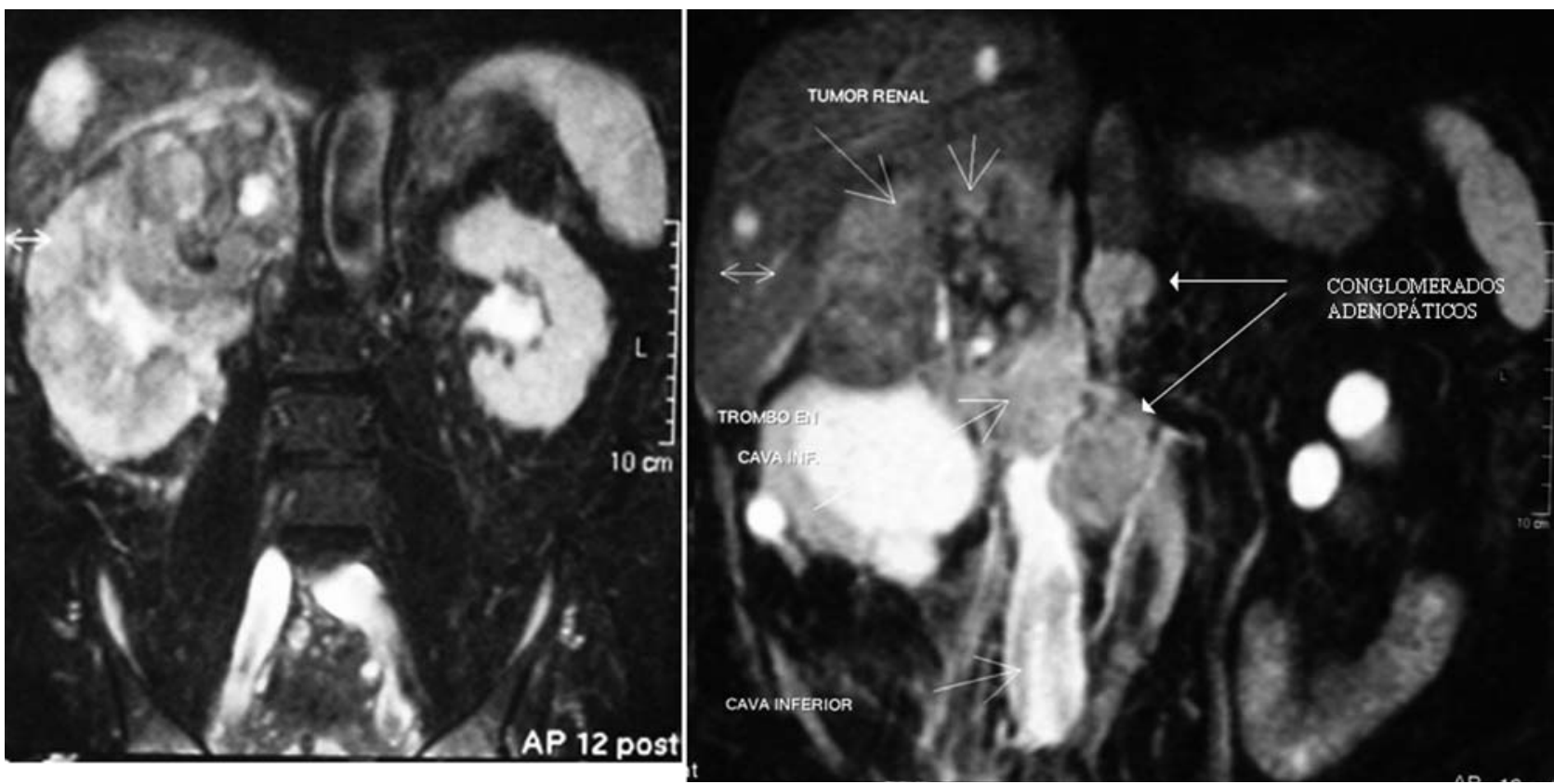

FIGURA 2. RMN. Cortes frontales del tumor renal derecho infiltrando la glándula suprarrenal, el trombo en la vena cava inferior y los conglomerados adenopáticos.

sentido craneocaudal. El trombo no afectaba a la vena renal izquierda, de localización retroaórtica como variante. Presencia de adenopatías patológicas en el espacio porto-cava, territorio del tronco celiaco, interaortocava y perirrenal, con gran adenopatía metastásica de $6 \times 4 \times 5 \mathrm{~cm}$ inferior al hilio renal derecho. Intensa captación de gadolinio heterogénea a nivel tumoral, perirrenal, adenopática y en el trombo intravascular. Las cadenas iliacas y las áreas pélvicas e inguinales eran normales. A nivel hepático, confirmación del angioma derecho y de múltiples quistes simples de pequeño tamaño.

La ecografía escrotal mostraba ambos testículos de morfología y ecoestructura normales, con un engrosamiento sólido heterogéneo a nivel del cordón espermático derecho en contacto con la cabeza del epidídimo.

Con el diagnóstico clínico de carcinoma renal estadio $\mathrm{T}_{3 \mathrm{~b}} \mathrm{~N}_{2} \mathrm{M}_{1}$, se realizó una nefrectomía radical derecha por toracofrenolaparotomía con linfadenectomía retroperitoneal de las masas adenopáticas, cavotomía con exéresis del trombo tumoral y finalmente una orquiectomía radical derecha por vía inguinal, evidenciándose el engrosamiento metastático del cordón espermático. El informe anatomopatológico confirmó el diagnóstico de carcinoma de células renales de tipo papi- lar de alto grado de malignidad (grado 3 de Fuhrman) con infiltración de la grasa perirrenal, la glándula suprarrenal, los vasos intrarrenales y la vena renal, con un índice de proliferación celular (Ki-67) moderado e inmunofenotipo CK-22 y vimentina positivos (Fig. 3). Presencia de extensas áreas de hemorragia y necrosis. Conglomerado adenopático de $5 \mathrm{~cm}$ con infiltración masiva por carcinoma renal de alto grado de malignidad con patrón de crecimiento sólido metastático. Trombo tumoral en cava correspondiente a carcinoma papilar renal. Testículo derecho con signos de atrofia leve y epidídimo sin afectación tumoral. Conducto deferente ensanchado por diferentes masas tumorales de hasta 4 cm de diámetro, presentando el cordón espermático múltiples vasos con ocupación tumoral e infiltración de tejidos blandos adyacentes, correspondiente a carcinoma de células renales de tipo papilar de alto grado de malignidad metastático por embolización vascular (Fig. 4).

En el postoperatorio el paciente presentó un tromboembolismo pulmonar con neumotórax apical izquierdo, siendo la evolución favorable al tratamiento mediante drenaje y anticoagulación. Así mismo, se produjo un episodio de hemorragia digestiva alta por ulcus gástrico que precisó esclerosis con adrenalina al 1/10000. La función 
renal izquierda postquirúrgica fue normal, con una creatinina de $1.3 \mathrm{mg} / \mathrm{dl}$. Planteada la falta de respuesta a la inmunoterapia de la variante histológica papilar asociada a estadio IV, se decidió seguimiento compartido con el servicio de cuidados paliativos. El paciente falleció a los 14 meses de la cirugía por infección respiratoria complicada con $\mathrm{CID}$, sin signos de recidiva o de nuevos focos macroscópicos metastásicos.

\section{DISCUSIóN}

El CCRP fue introducido como entidad morfológica diferente por Mancilla-Jiménez en 1976. Una mejor interpretación de los rasgos histológicos y genéticos llevaron a Kovacs y posteriormente a Störkel a plantear la clasificación actual del carcinoma de células renales en la que el subtipo papilar representa un 10-15\% del total, siendo el $2^{\circ}$ en frecuencia. Según $\operatorname{Amin}^{2}$, se considera que un tumor es un CCRP cuando presenta una arquitectura papilar o tubulopapilar predominante sin células de citoplasma claro, sin definir un porcentaje de componente papilar mínimo necesario, existiendo variantes sólidas con las mismas alteraciones genéticas e inmunohistoquímicas $^{8}$. A diferencia del CCRC se cree que derivaría de los elementos más distales de la nefrona, aunque hay autores que establecen el origen de todo carcinoma renal en una célula epitelial renal pluripotencial. El CCRP presenta características citogenéticas propias hasta el punto de que un tumor de arquitectura papilar que carezca de estos cambios genéticos no debe ser clasificado como CCRP, si bien no se recomienda el análisis genético actualmente de forma sistemática ${ }^{9}$. En este subtipo, la alteración del cromosoma $3 p$ no influye en la carcinogénesis, a diferencia del convencional.

Kovacs ${ }^{10}$ propuso el desarrollo de este tumor a partir de adenomas papilares corticales, a menudo presentes, los cuales asocian trisomías de los cromosomas 7 y 17, dependiendo la degeneración maligna de adicionales polisomías de los cromosomas 16 (69\%), 12 (28\%), y 20 (28\%). La delección del cromosoma Y se encuentra en el 92\% de los varones. La tendencia del CCRP a ser hipovascularizado (2/3) se explica citogeneticamente por la ausencia típica de mutaciones del gen VHL que regularía la principal molécula angiogénica ${ }^{11}$. En el 96\% de los casos el tumor es esporádico. Se da en pacientes de edad avanzada, con asociación más frecuente a la enfermedad quística renal adquirida secundaria a insuficiencia renal crónica $^{12}$. Sólo un 4\% son bilaterales, aunque presenta multifocalidad en el 39-49\%, con mucha mayor frecuencia que el convencional, si bien se encuentran limitados al riñón más del 80\% al diagnóstico con predominio de localización polar $(3: 1)^{2}$. Histológicamente presenta una pseudocápsula fibrosa, con típicas áreas de hemorragia y necrosis que pueden ocupar hasta un 70\% del tumor. La transformación sarcomatoide, asociada a comportamiento agresivo, es infrecuente. Más del 75\% de los casos son de grado nuclear 2 de Fuhrman.

El CCRP se ha considerado un subtipo de mejor pronóstico por la presentación de un mayor porcentaje de casos en estadios precoces ${ }^{1}$ y un teórico menor potencial de malignidad, presentando supervivencias más prolongadas independientemente del estadio ${ }^{2}$, con tasas de mortalidad inferior por cáncer metastático que el CCRC. Sin embargo hay casos como el que aportamos con un desarrollo muy agresivo en probable relación con la subdivisión del CCRP propuesta por Delahunt y Eble ${ }^{4}$ en dos variantes histológicas con diferente comportamiento clinico. El subtipo 1 con papilas revestidas por células cuboideas basófilas de núcleos uniformes es más infrecuente, asocia mutaciones c-MET, se observa en los casos hereditarios y es de mejor pronóstico. El subtipo 2 con grandes células columnares eosinofílicas, núcleos pleomórficos y nucleolos prominentes, es más frecuente en formas esporádicas, se asocia a grado nuclear de Fuhrman más alto, estadios avanzados con peor evolución clínica y pronóstico ${ }^{13}$, sin mutaciones c-MET, de modo que la ganancia del número de copias del MET nativo resultaría suficiente para la génesis del tumor. La inmunohistoquímica también ayuda a identificar a los pacientes con alto riesgo de progresión tumoral. Así, la elevación del índice Ki-67 es un indicador pronóstico adicional de agresividad biológica, correlacionado con el grado nuclear y con la supervivencia ${ }^{14}$. El $50 \%$ expresan además vimentina, asociada a la diferenciación sarcomatoide. Nuestro paciente debutó con hematuria macroscópica, presente de 

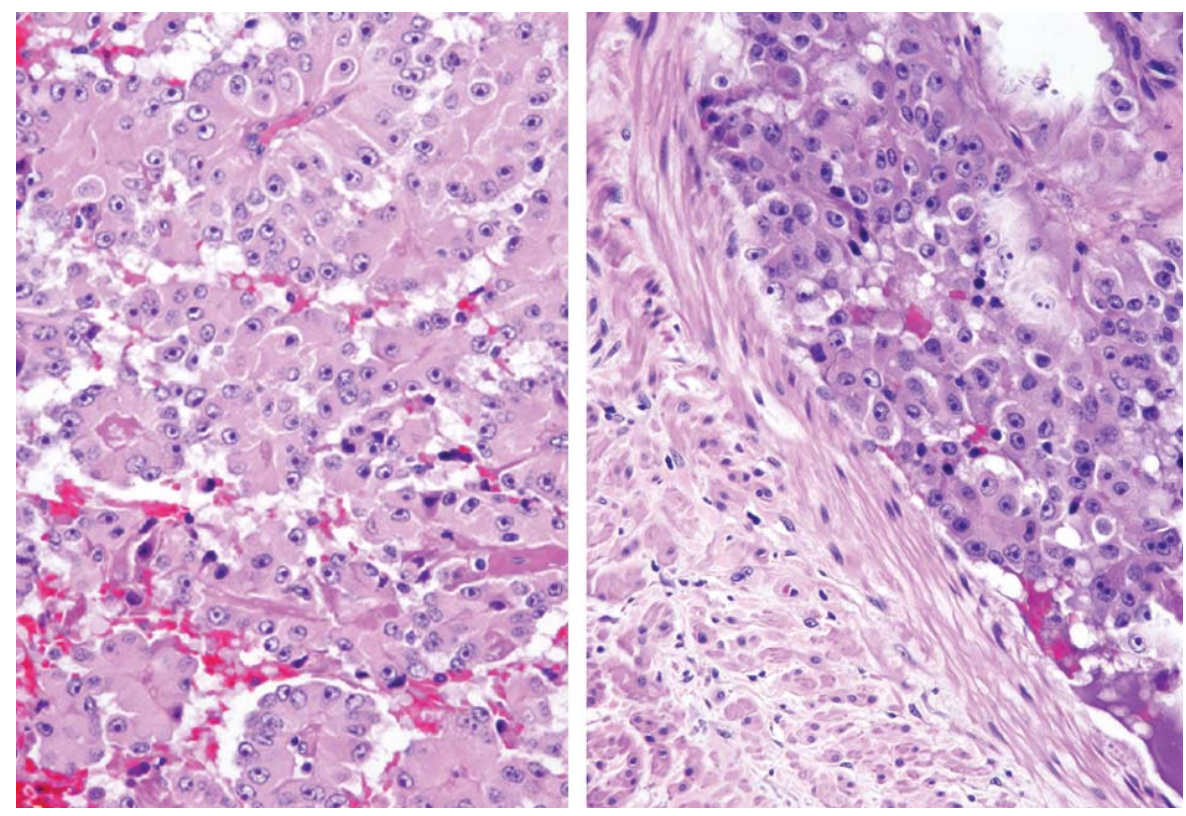

FIGURA 3. Carcinoma de células renales, tipo papilar 2. Células grandes con citoplasma voluminoso, eosinófilo y núcleo grande y esférico con nucleolo prominente.
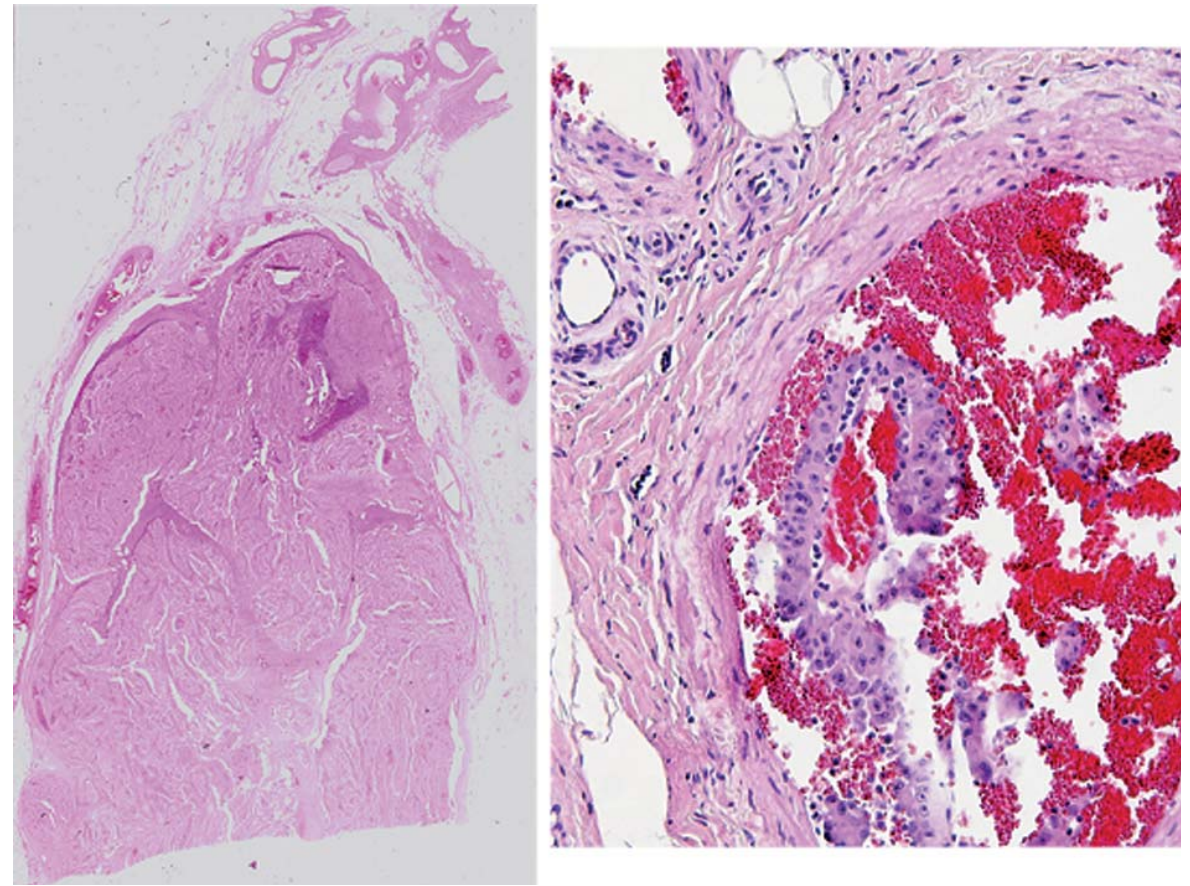

FIGURA 4. Carcinoma de células renales, tipo papilar 2. Infiltración vascular en el cordón espermático. Macro-micro. Hematoxilina-Eosina.

forma aislada en un $20 \%$ de los casos y con metástasis palpable en el cordón espermático derecho sincrónica. Las metástasis sincrónicas aparecen en un $15-25 \%$ de todos los carcinomas renales, siendo sintomáticas sólo el 28\%. El 1,6-3,2\% de todos los pacientes presentan una metástasis solitaria ${ }^{15}$.
La afectación por orden de frecuencia sería pulmón (50$60 \%$ ), hígado, hueso, cerebro, suprarrenal y riñón contralateral. En los raros casos de metástasis localizadas en cordón espermático y epidídimo, resulta aún más infrecuente el hallazgo sincrónico puesto que la metástasis intraescrotal suele ser un evento tardío y posterior a la detección del tumor renal primario y no un signo de presentación clínica como ocurrió en nuestro paciente, si bien el hallazgo resulta más excepcional para la variante histológica de tipo papilar. Cuando la metástasis es sincrónica el pronóstico es aún peor con supervivencias inferiores a un año, aunque Han refiere que el pronóstico en estos casos depende del número de órganos afectados más que de la afectación individual de cualquiera de ellos ${ }^{16}$.

El compromiso del sistema venoso característico del cáncer renal y mucho más frecuente que en cualquier otro tipo de tumor, afecta a la vena cava en el $4-10 \%$ de los casos y explica en nuestro paciente la vía de diseminación hematógena retrógrada a través de la vena espermática hacia el cordón. La $\mathrm{RM}$ fue nuestra técnica diagnóstica de elección al no ser invasiva ni nefrotóxica, superando a la TAC para la evaluación de la extensión, invasión y tipo de trombo en la vena cava, por su mayor especificidad en el estadiaje de los ganglios linfáticos retroperitoneales diferenciándolos de los vasos y por su calidad en la valoración de la extensión tumoral a las estruc- 
turas circundantes, demostrando en nuestro paciente la invasión de la grasa perirrenal y de la glándula suprarrenal por contigüidad, únicamente presente en el $1-2 \%$ de los $\operatorname{casos}^{15}$. La invasión directa de la pared venosa tiene mayor valor pronóstico que la extensión cefálica del trombo tumoral. Su influencia negativa sobre la supervivencia se ha intentado modificar resecando la pared infiltrada. Aunque la incidencia de afectación ganglionar retroperitoneal ocurre en el 9-32\%, la invasión venosa aumenta este porcentaje al 60\%. La mitad de los pacientes con ganglios positivos tienen metástasis a distancia siendo su pronóstico peor que la afectación venosa o de la grasa perinéfrica.

El CCRP parece tener mayor propensión por la invasión locorregional y por la diseminación linfática ${ }^{17}$. La linfadenectomía no ha demostrado incrementar la supervivencia, que depende del comportamiento biológico del tumor como resultado de complejas interacciones entre múltiples factores. Para la nefrectomía radical derecha debe ser latero, pre, retro e interaortocava y no solo hiliar ya que la estación primaria es la retroperitoneal. A los factores pronósticos desfavorables de nuestro paciente ya comentados, siendo el estadio el más importante, con invasión de la grasa perinéfrica y de la glándula suprarrenal homolateral, trombo tumoral en la vena cava inferior, metástasis sincrónica en el cordón espermático derecho, grado nuclear 3 de Fuhrman como segundo factor en importancia, subtipo histológico papilar 2, indice Ki-67 moderado y vimentina positiva, habría que añadir la presencia de anemia (20-40\%), la elevación de las enzimas hepáticas, la hematuria macroscópica y la masa abdominal palpable en relación con un tamaño tumoral mayor de $10 \mathrm{~cm}$, asociado a supervivencias a 5 años del $0 \%$ por su gran tendencia a las metástasis. Sin embargo no presentó otros datos clínicos de mal pronóstico como la perdida de peso mayor del $10 \%$, el deterioro del estado clínico o dolores óseos, ni bioquímicos como la elevación de la VSG ( $>30 \mathrm{~mm} / \mathrm{h})$, de la fosfatasa alcalina o de la calcemia $(>10 \mathrm{mg} / \mathrm{dl})$. La existencia de necrosis tumoral, más frecuente en el tumor papilar, se ha asociado con la supervivencia, aumentando 3 veces la probabilidad de fallecimiento ${ }^{18}$. Bretheau et al. ${ }^{3}$ encontraron correlación entre el grado nuclear de Fuhrman, el estadio tumoral, la presencia de metástasis sincrónicas, la afectación de ganglios linfáticos, la existencia de trombo tumoral venoso, el tamaño tumoral y la invasión del tejido adiposo perinéfrico, cuya influencia parece ser aditiva. La afectación de ganglios linfáticos y las metástasis de órganos a distancia conllevan un pronóstico ominoso que no se modifica significativamente con la cirugía radical $^{15}$, falleciendo la mayoría en el plazo de 1 año tras la nefrectomía sin tratamiento sistémico. $\mathrm{El}$ efecto beneficioso de la cirugía radical como único tratamiento es más frecuente en pacientes con un único foco metastásico resecable, con nivel funcional ECOG 0 o 1 y menos de 60 años, aunque este fenotipo clínico favorable sólo ocurre en el 1-3\% de los casos. La posibilidad de una exéresis completa del tumor resulta un importante factor pronóstico. La toracofrenolaparotomía está indicada en tumores renales derechos de polo superior y de gran tamaño, sobre todo en obesos, aunque es más traumática y requiere mayor tiempo quirúrgico. La mortalidad perioperatoria conocida del 5-10\% en pacientes con trombo en la cava inferior podría contraindicar una cirugía agresiva en casos de trombo tumoral venoso con ganglios macroscópicamente positivos y con metástasis demostrables ${ }^{19}$. El cáncer renal metastásico se ha considerado enfermedad quirúrgica con intención paliativa o citorreductora previa a tratamiento sistémico, aunque el CCRP parece no responder a la inmunoterapia, por lo que su tratamiento sigue siendo paliativo.

En conclusión, más allá de aportar como hallazgo excepcional la metástasis atípica sincrónica en el cordón espermático de un carcinoma renal papilar, corroboramos que las implicaciones pronósticas de esta variante tumoral no han sido aún bien definidas, siendo el estadio el único parámetro pronóstico predictivo de su comportamiento clínico ${ }^{2}$ con la metástasis sincrónica como peor factor, de modo que en comparaciones controladas por tamaño y estadio no hay diferencias con el CCR convencional, siendo necesario incorporar en los análisis multivariantes la estratificación por subtipos del CCR papilar para conocer el valor pronóstico individual con repercusión en el algoritmo de decisiones terapéuticas y de seguimiento ${ }^{1}$. 


\section{REFERENCIAS}

1. Beck SD, Patel MI, Snyder ME, Catan MW, Motzer RJ, Reuter VE, et al. Effect of papillary and chromophobe cell type on disease-free survival after nephrectomy for renal cell carcinoma. Ann Surg Oncol. 2004;11(1):71-77.

2. Amin MB, Corless CL, Renshaw AA, Tickoo SK, Kubus J, Schultz DS. Papillary (chromophil) renal cell carcinoma: histomorphologic characteristics and evaluation of conventional pathologic prognostic parameters in 62 cases. Am J Surg Pathol. 1997;21(6):621-635.

3. Bretheau D, Lechevallier E, de Fromont M, Sault MC, Rampall M, Coulange C. Prognostic value of nuclear grade of renal cell carcinoma. Cancer. 1995;76(12):2543-2549.

4. Delahunt B, Eble JN. Papillary renal cell carcinoma: a clinicopathologic and immunohistochemical study of 105 tumors. Mod Pathol. 1997;10(6):537-544.

5. Gohji K, Nakanishi T, Yoshimura K, Kamidono S. Metastatic tumor of the spermatic cord from renal cell carcinoma. Hinyokika Kiyo. 1990;36(7):827-829.

6. Lioe TF, Biggart JD. Tumours of the spermatic cord and paratesticular tissue. A clinicopathological study. $\mathrm{Br} \mathrm{J}$ Urol. 1993;71(5):600-606.

7. Hicks JA, Britton JP, Carter PG, Conroy B. A right-sided renal carcinoma uniquely presenting as a mass in the spermatic cord. Urol Int. 2003;70(3): 247-248.

8. Renshaw AA, Zhang H, Corless CL, Fletcher JA, Pins MR. Solid variants of papillary (chromophil) renal cell carcinoma: clinicopathologic and genetic features. Am J Surg Pathol. 1997;21(10):1203-1209.

9. Bostwick DG, Eble JN. Diagnóstico y clasificación del carcinoma de células renales. En McGraw-Hill Interamericana Editores SA. Clínicas de Urología de Norteamérica. Anatomía Patológica en Urología. Volumen 3. Méjico, McGrawHill Interamericana1999, pp 663-671.

10. Kovacs G, Fuzesi L, Emanuel A, Kung HF. Cytogenetics of papillary renal cell tumors. Genes Chromosomes Cancer. 1991;3:249-255.

11. Blath RA, Mancilla-Jimenez R, Stanley RJ. Clinical comparison between vascular and avascular renal cell carcinoma. J Urol. 1976;115(5):514-519.

12. Pavlovich ChP, Schmidt LS, Phillips JL. Bases genéticas del carcinoma renal. En McGraw-Hill Interamericana
Editores SA. Clinicas Urológicas de Norteamérica. Tratamiento actual del carcinoma renal. Volumen 3. Madrid, McGraw-Hill Interamericana 2003, pp 423-440.

13. Delahunt B, Eble JN, McCredie MR, Bethwaite PB, Stewart $\mathrm{JH}$, Bilous AM. Morphologic typing of papillary renal cell carcinoma: comparison of growth kinetics and patient survival in 66 cases. Hum Pathol. 2001;32(6):590-595.

14. Mulders P, Bleumer I, Oosterwijk E. Antígenos y marcadores tumorales del carcinoma renal. En McGraw-Hill Interamericana Editores SA. Clínicas Urológicas de Norteamérica. Tratamiento actual del carcinoma renal. Volumen 3. Madrid, McGraw-Hill Interamericana 2003, pp 441-451.

15. Novick AC, Campbell SC. Tumores renales. En Walsh PC, Retik AB, Vaughan ED, Wein AJ, editors. Campbell Urología $8^{\text {a }}$ Edición, Tomo 4. Madrid, Editorial Médica Panamericana 2005, pp 2911-2979.

16. Han KR, Pantuck AJ, Bui MH, Shvarts O, Freitas DG, Zisman A, et al. Number of metastatic sites rather than location dictates overall survival of patients with nodenegative metastatic renal cell carcinoma. Urology. 2003;61 (2):314-319

17. Renshaw AA, Richie JP. Subtypes of renal cell carcinoma. Different onset and sites of metastatic disease. Am J Clin Pathol. 1999;111(4):539-543.

18. Amin MB, Tamboli P, Javidan J, Stricker H, de-Peralta Venturita M, Deshpande A, et al. Prognostic impact of histologic subtyping of adult renal epithelial neoplasms: an experience of 405 cases. Am J Surg Pathol. 2002;26(3): 281-291

19. Kontak JA, Campbell SC. Factores pronósticos en el carcinoma renal. En McGraw-Hill Interamericana Editores SA Clínicas Urológicas de Norteamérica. Tratamiento actual del carcinoma renal. Volumen 3. Madrid, McGraw-Hill Interamericana 2003, pp 453-466.

Correspondencia autor: Dr. M. Pascual Samaniego

Servicio de Urología. Hospital San Pedro de Alcántara.

Avda. Pablo Naranjo, s/n. 10003 Cáceres. Tel.: 927621582

E-mail autor: mpaski10@yahoo.es

Información artículo: Nota clínica

Trabajo recibido: abril 2006

Trabajo aceptado: junio 2006 